\title{
The Role of Simulator Promis2 in Learning Laparoscopic Skill
}

\author{
Shrestha SK, ${ }^{1}$ Nomura T, ${ }^{2}$ Tajiri T, ${ }^{2}$ Akagi I,${ }^{2}$ Aso $R,{ }^{2}$ Miyashita $M,{ }^{2}$ Yoshimura $A,{ }^{3}$ Shimura ${ }^{3}$ \\ 'Department of Surgery, Kathmandu Medical College, Kathmandu, Nepal, ${ }^{2}$ Department of surgery, ${ }^{3}$ Department of Clinical Simu- \\ lation, Nippon Medical School, Tokyo, Japan.
}

\section{ABSTRACT}

Introduction: Laparoscopic surgery is unique and complex in nature, so the training is necessary before proceeding to operation room. Many computer aided simulators have been developed for the purpose. Our objective is to assess the improvement of basic laparoscopic skills after training in simulator.

Methods: The fifth year medical students underwent training of three laparoscopic skills using Promis2 simulator twice weekly for 4-6 weeks. The skills are laparoscopic orientation, target pointing and objects transferring. Time, path length of instruments and economy of movements were recorded. The comparisons were made for these parameters between session first and the last using a MannWhitney U test.

Results: Ten volunteers completed the exercises in less time (186.3 \pm 55.4 seconds) than the first exercise (215.7 \pm 57.4 seconds) $(\mathrm{P}=0.0027)$. Both the right and left hand instrument path lengths were also improved from $4425.8 \pm 1284.3 \mathrm{~mm}$ in the first exercise to $3925.3 \pm 1313.6 \mathrm{~mm}$ in the last exercise in the left side $(\mathrm{P}=0.0219)$ and likewise from $4273.8 \pm 1859.4 \mathrm{~mm}$ to $3831.3 \pm 1717.4 \mathrm{~mm}$ in the right side $(\mathrm{P}=0.0027)$. Economy of the movement in the left handed instrument improved from $1114.4 \pm 453.5$ $\mathrm{mm}$ in the first exercise to $966.8 \pm 411.1 \mathrm{~mm}$ in the last $(\mathrm{P}=0.0443)$ and in the right handed instrument from $845 \pm 398.8 \mathrm{~mm}$ to $771.4 \pm 370.5 \mathrm{~mm}$ according to the software of Promis2 simulator $(\mathrm{P}>0.005)$.

Conclusions: Training in Promis2 simulator improves the basic laparoscopic skills. The candidates become consistently faster with shorter path lengths and had smoother instruments movements. They also became significantly more consistent in their performance.

Key Words: laparoscopy, promis2, simulator, training

\section{INTRODUCTION}

Hand and eye coordination and use of long instruments through the fixed points are necessary skills in laparoscopy surgery. Practice on patients is no longer considered acceptable. ${ }^{1,2}$ Animal laboratories are costly because it needs separate infrastructures, instruments and disposal problem.
Cadaver training is tried in some parts of the world but lacks bleeding, tissues get tougher as time passes, preservation is expensive and this is not practical in this part of the world. ${ }^{3}$

Simulators have been successfully practiced in flight training, astronauts, war environments and driving before going to actual fields..$^{4-6}$ It allows mistakes

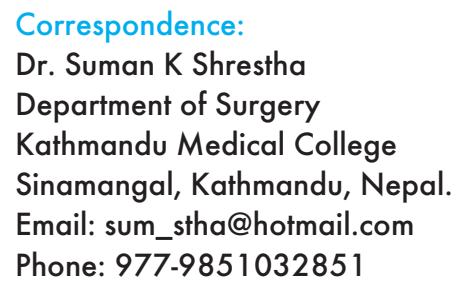


Shrestha et al. The Role of Simulator Promis2 in Learning Laparoscopic Skill

in consequences free environment. ${ }^{7,8}$ Virtual reality simulators are expensive (150000 US \$) and gives ghostly feeling. Augmented reality simulators are cheaper, provides almost same exercises. ${ }^{9,10}$ The technical expertise will depend on inherited genetic abilities, modulated by acquired knowledge, experience and improved by practice. ${ }^{11-15}$ The aim of this study is to assess the role of simulator in the improvement of laparoscopic skills.

\section{METHODS}

An observational study was conducted at Nippon Medical School, Sendagi, Tokyo. Students were included in this prospective study from 2007 September till 2007 November. Institutional approval and consent was taken. Only the students who have interest in surgical career are included in the study and those who did not want to continue after one exercise were excluded. All volunteers were instructed and shown about the use of laparoscopic camera, instruments on the simulator before starting exercise. They are asked about interest of career in surgery. The permission from the ethical committee was obtained. Comparisons of mean performance were made between the first and last exercises using a Mann-Whitney $U$ test. Statistical analysis and data collection were done by using Microsoft Excell 2003.

The Promis2, augmented reality simulator (Haptica) is used for simulation training. It is based on Sony Vaio note book computer, Pentium4, Windows Xp. The laparoscopic interface consists of a torso shaped metallic mannequin 29" 20" 9" with a black neoprene cover connected to the computer with standard four pin digital cable. Laparoscope camera is positioned at the symphysis pubis of mannequin and views displayed on the computer screen. The distal ends of laparoscopic instrument shafts are covered with two pieces of yellow electric tape to serve a reference point for camera tracking system. The permission was taken from the company but the study was not sponsored by them.

\section{Simulator Training Procedure}

Volunteers practiced three exercises at a time.

Exercise 1: Camera navigation also called investigation; is searching the object by camera, focusing it and steadying for five seconds and pressing the foot pedal for repeating the same maneuver at other site. Right upper quadrant, left upper quadrant, left lower quadrant and central abdomen are pointed by the laparoscope in the same manner.

Exercise 2: Object transferring. In this exercise, beads are transferred from one cup to other by right hand and then to next cup by left hand and press the foot pedal after completion(Figure 2 and 3).

Exercise 3: Object pointing. This is to touch the object until it disappears and press the foot pedal to point to next object.

The path length of instrument is distance traveled by it. Economy of movement is calculation of smoothness avoiding unnecessary movement. The record of time in seconds to complete the tasks, path lengths of the instruments in millimeters, economy of movements in millimeters were recorded all from session one to six and compared from session one to sixth to assess the improvement. The measurements are recorded according to the software in the promis simulator.

\section{RESULTS}

Total 10 volunteers completed the final exercises in less time (186 \pm 55.6 seconds) than the first exercise $(215.7 \pm 57.4$ seconds) $(P=0.0027)$ (Figure 1). Both the right and left hand instruments path lengths also improved from $4425.8 \pm 1284.3 \mathrm{~mm}$ in the first exercise to $3925.3 \pm 1313.6 \mathrm{~mm}$ in the last in the left side $(P=0.0219)$ and likewise from $4273.8 \pm 1859.4 \mathrm{~mm}$ to $3881.3 \pm 1717.4 \mathrm{~mm}$ in the right side $(P=0.0027)$ (Figure 2).

Economy of the movement in the left handed instrument improved from $1114.4 \pm 453.5 \mathrm{~mm}$ in the first exercise to $960.8 \pm 411.1 \mathrm{~mm}$ in the last ( $p$-value:0.0443) and in the right handed instrument from $845 \pm 398.8 \mathrm{~mm}$ to $771.4 \pm 370.5 \mathrm{~mm}$ according to the software of Promis 2 simulator $(\mathrm{P}>0.005)$ (Table 1).

With the results of interview, subjects showed interests in surgical skills improved after completing all exercises. Before training, they had no idea about joining the surgical department, but after training, they showed increased possibility of joining surgical department in future. The confidence in skills after the training improved except in one who couldn't find the difference (Figure 2).

\section{DISCUSSION}

Total time taken to complete the exercises by laparoscopic novices was $421.5 \pm 128$ seconds in Sickle $\mathrm{KRV}$ et al study where as it was $186 \pm 55.4$ seconds in the first exercise and $186 \pm 55.4$ seconds in the last exercise in our study. Likewise the pathlengths of the instruments were $4081 \pm 138 \mathrm{~mm}$ in that study and $4425 \pm 1284.3 \mathrm{~mm}$ in the left side and $4273.8 \pm 1859.4$ $\mathrm{mm}$ in right side in our study. Economy of movements was $2487 \pm 92 \mathrm{~mm}$ in that study and $1114.4 \pm 435.5$ $\mathrm{mm}$ in the left side and $845.6 \pm 398.8 \mathrm{~mm}$ in the right side in the first exercise in our study. The difference was because of task difference, suturing in their study and object handling in our study. 
Shrestha et al. The Role of Simulator Promis2 in Learning Laparoscopic Skill

Table 1. Results of tasks in the first and last exercises

\begin{tabular}{llll}
\hline & 1st exercise & Last exercise & P-value \\
\hline Time (sec) & $215 \pm 57.4$ & $186 \pm 55.4$ & 0.0027 \\
Left Instrument Path $(\mathrm{mm})$ & $4425.8 \pm 1284.3$ & $3925.3 \pm 1313.6$ & 0.0129 \\
Left Instrument of economy of movement $(\mathrm{mm})$ & $1114.4 \pm 453.5$ & $960.8 \pm 411.1$ & 0.0443 \\
Right Instrument Path $(\mathrm{mm})$ & $4273.8 \pm 1859.4$ & $3881.3 \pm 1717.4$ & 0.0027 \\
Right Instrument economy of movement $(\mathrm{mm})$ & $845.6 \pm 398.8$ & $771.4 \pm 370.5$ & Not significant \\
\hline
\end{tabular}

The growing need for both psychomotor skills training and objective assessment in minimally invasive surgery has led to the dramatic improvements in surgical simulation technology. ${ }^{9,16}$ The study contributes to a growing evidence that, under very specific training conditions, virtual reality simulation can be used to improve operative surgical skills. ${ }^{17}$ The use of computer enhanced surgical skills training has increased with the availability of progressively more capable devices and urgent mandate to accomplish such training. Surgical tools are predicted to serve a more important role in both acquisition and maintenance of the surgical skills in the future. ${ }^{18}$ Simulators allow for repeated practice of standardized tasks under reproducible conditions and facilitate the use of objective measures to assess performance. Transfer of skills from simulation to clinical environment has been shown for laparoscopic manipulative tasks with improved performance of laparoscopic cholecystectomy in randomized controlled trials. ${ }^{13,19}$

In this study, the candidates were consistently faster, had shorter path lengths and had smoother instruments movements in the last exercise than in the first one. They also became significantly more consistent in their performance in the last exercise. They all showed improvements across all three measures from exercise one to last, even due to variability of their performance. Nobody had previous experience of assisting

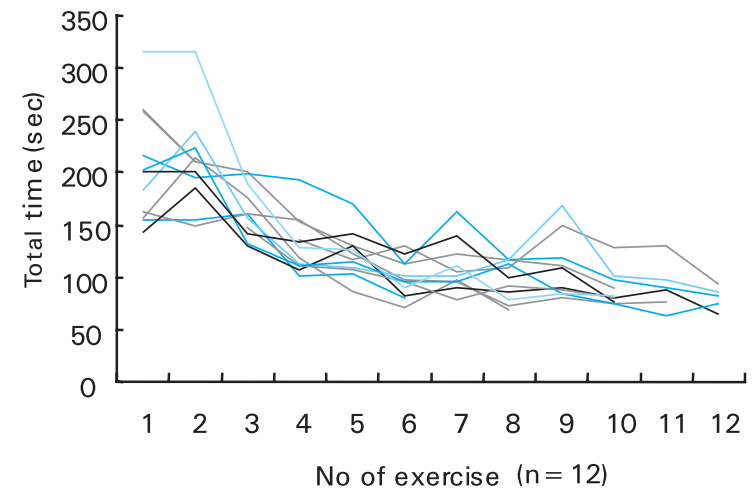

Figure 1. A graph showing time required to complete the tasks from exercise one to six. laparoscopic surgery.

Future studies will need to address whether Promis2 training leads to transfer validity to animate operating room for the basic laparoscopic skills: camera navigation, efficient instrument motion and perceptual ability. The use of simulation training for MIS skills allows for the development of a pretrained novice so that the basic psychomotor and Visio spatial laparoscopic skill have been developed and become reasonably automatic before proceeding to operation room. This allows for more efficient and safer use of operating room training time to be focused on clinical decision making and avoidance of errors rather than learning how to use and manipulate the equipment. ${ }^{4}$

The population is small for at most 10 students come for 4-6 weeks. Only multi institutional candidates make the adequate subjects number. And the expensive equipment can't be afforded in every college. Again the centre for multinational practice will be feasible. Transfer validity of the study can only be done when the students pass the examination and come to surgical department as interns. At the same time the durability of the training can be assessed with repeating the same exercises in the same simulator after a year and compare with previous results. We didn't compare with other training modalities as this is the study of acquisition of basic skills necessary for the laparoscopic surgery.

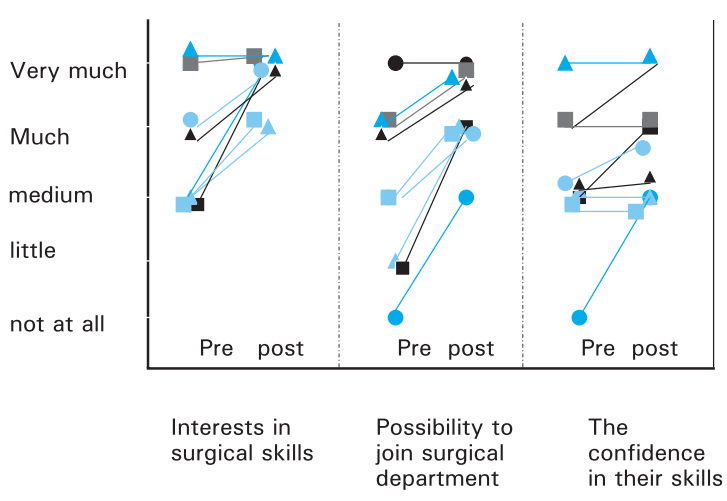

Figure 2. Results of questionnaire to the students 
The device used in this study, Promis2, augmented reality simulator, shows promising preliminary results. Construct validity was clearly demonstrated by the results of the tasks that the simulator can clearly distinguish between the first and last exercises. ${ }^{20}$ An attractive feature of the Promis2 simulator is that the measure of instrument path length and smoothness represent technically more precise and tightly defined performance measures. The use of vision tracking for the motion analysis in the Promis2 simulator has great potential both as a training tool and a means of assessing laparoscopic surgical skills. ${ }^{9}$

The laparoscope has potential to provide a view of field superior to that obtained with the naked eye. Moreover the view is equally available to assistant and scrub staff as well. ${ }^{21}$ Camera navigation is of fundamental importance on any laparoscopic operation. The potential implications of poor telescope use include surgeon frustration, longer procedures and compromised patient safety. Despite these potential problems, sophisticated tools to teach these skills in the training have only recently become available. Promis 2 is the simulator device to very specifically address the skills training issue for users of laparoscopic telescopes. This study focus on the novice users irrelevant to the real world experience of institutions involved in medical student training and of hospitals that use non surgeon first assistant. Despite the ability to make assessment or even practice surgical skills in the animal lab, issues including cost, proximity, personnel, facility, maintenance and ethical concerns contribute effective barriers to the use of animate models for this purpose. Some of the obstacles to implementation of simulation training methods includes procurement of device, lack of force feedback capabilities in more affordable systems and perception of technology intensiveness.

These might intimidate some potential users and raise fears in others of rapid device obsolesce. Although some of these concerns are valid and must be addressed by developers and educators, the growing experience with current surgical devices with assessment capabilities used on formative training tools in the course of proficiency based training has shown that they are highly practical and of significant educational value. ${ }^{13}$ Certain skills will likely to be best learned in high fidelity models, while complex tasks like suturing and knot tying may equally or even better in less expensive lower fidelity models like traditional box trainer. ${ }^{4}$

Advanced minimal invasive surgery is no longer the surgery of future, it is here today and we need to train residents to be proficient in the skills. ${ }^{4}$ Training to students, even lack of time, they are regularly studying the text books in the intervals for the problems when encounter in clinical practice. Likewise, simulation training can be regulated before going to operation room and do the same practice. The simulation system represents useful training device for learning laparoscopic skills and should be widely used to improve surgical performance. ${ }^{1}$ And the more surgical modules available (laparoscopic Nissen fundoplication, laparoscopic inguinal hernia, laparoscopic appendectomy, laparoscopic colon surgery, bariatric procedures), the more interesting the simulation system will be. ${ }^{14}$ The surgeons who participate in the simulation training system, experienced significant improvements in their laparoscopic skills regardless of prior level of expertise. Surgeons, who are adept at performing conventional surgery, possess the knowledge of surgical principles and skills of operative manipulation. To become proficient in laparoscopic surgery, they need to master only the necessary adaptation in visual motor processing through training and practice. ${ }^{11}$

Virtual reality training is more likely to be successful if the training schedule placed on an interval basis rather than massed into a short period of extensive practice. High fidelity virtual reality simulators will confer the greatest skill transfer to the in vivo surgical simulation but less expensive simulator training will also lead to considerably improved skill generations. ${ }^{7}$ But still, the constraints of loss of tactile sensation in the laparoscopic tools and fulcrum effect causing the requirement for opposing motion of action is very real to the environment of laparoscopic surgery. ${ }^{5}$

\section{CONCLUSIONS}

The training in augmented reality simulator Promis 2 is helpful for acquiring the basic laparoscopic skills. The candidates were consistently faster, had shorter path lengths and had smoother instruments movements. They also became significantly more consistent in their performance. This type of training could be included in the surgical curriculum. However, more study is required to validate the authenticity of the study with control.

\section{REFERENCES}

1. Schijven M, Jakimowicz J. Face-, expert, and referent validity of the Xitact LS500 laparoscopy simulator. Surg Endosc. 2002 Dec;16(12):1764-70. Epub 2002 Jul 8.
2. van Dongen $\mathrm{KW}$, Tournoij E, van der Zee DC, Schijven MP, Broeders IAMJ. Construct validity of Lapsim: Can the Lapsim virtual reality simulator distinguish between novices and experts? Surg Endosc. 2007;21:1413-7. 
3. Kirby TO, Numnum TM, Kilgore LC, Straughn JM. A prospective evaluation of a simulator based laparoscopic training programme for gynecology residents. J am col surg. 2007;206(2):343-8.

4. Pamela BA, Derek TW, John DB, Rajani KY, Gerard MD, Paul GG, et al. Laparoscopic skills are improved with lapmentor training, results of a randomized, double blinded study. Ann surg. 2006;243:854-63.

5. Panait L, Merrell RC, Rafiq A, Dudrick SJ, Broderick TJ. Virtual reality laparoscopic skill assessment in microgravity. J Surg Res. 2006 Dec;136(2):198-203.

6. Hassan I, Gerdes B, Koller M, Dick B, Hellwig D, Rothmund $\mathrm{M}$, et al. Spatial perception predicts laparoscopic skills on virtual reality laparoscopy simulator. Childs Nerv Syst. 2007;23:685-9.

7. Gallagher A, Ritter E, Higgins G, Fried MP, Smmith CD, Satava RM . Virtual Reality Simulation for the operating Environment. Proficiency - based training as a paradigm shift on suture training. Ann Surg. 2005;241(2):364-72.

8. Yamaguchi S, Konishi K, Yasunaga T, Yoshida D, Kinjo $\mathrm{N}$, Kobayashi $\mathrm{K}$, et al. Construct validity for eye hand coordination skill on a virtual reality laparoscopic surgical simulator. Surg Endosc. 2007;21:2253-7.

9. Sickle KRV, McClusky DA, Gallagher AG, Smith CD. Construct validation of the ProMIS simulator using a novel laparoscopic suturing task. Surg Endosc. 2005;19:1227-31.

10. Botden SMBI, Buzink SN, Schijven MP, Jakimowicz JJ. Augmented versus virtual reality simulation: what is the difference? World J Surg. 2007;31:764-72.

11. Harrith MH, Nakka VAK, Juancho E. Training Simulator for developing laparoscopic skills. JSLS. 2001;5:255-65.

12. Elneel FHF, Carter F, Tang B, Cuschieri A. Extent of innate dexterity and ambidexterity across handedness and gender: implications for training in laparoscopic surgery. Surg Endosc. 2008;22:31-7.
13. G Sabha, AD Joseph, RSL Myron, Giavonni ML, Neal ES. Virtual-reality training improves angled telescope skills in novice laparoscopists. Am J Surg. 2007;193:260-5.

14. Stefannidis D, Haluck R, Fam T, Dunne JB, Reinke T, Markley $\mathrm{S}$, et al. Construct and face validity and task workload for laparoscopic camera navigation: virtual reality versus video trainer systems at the SAGES Learning Center. Surg Endosc. 2007;21:1158-64.

15. McCluney Al, Vassiliou MC, Kaneva PA, Cao J, Stanbridge DD, Feldman LS, et al. FLS simulator performance predicts intraoperative laparoscopic skills. Surg Endosc. 2007;21:1991-5

16. Stefanidis D, Korndorffer JR, Heniford BT, Scott DJ. Limited feedback and video tutorials optimize learning and resource utilization during laparoscopic simulator training. Surgery. 2007;142:202-6.

17. Bruynzeel H, de Bruin AFJ, Bonjer HJ, Lange JF, Hop WCJ, Ayodeji ID, et al. Desk top simulator: key to universal training? Surg Endosc. 2007;21:1637-40

18. Stefanidis D, Korndorffer JR, Markley S, Sierra R, Heniford BT, Scott DJ. Closing the gap in operative performance between novices and experts: Does harder mean better for laparoscopic simulator training? J Am Coll Surg. 2007;205:307-13.

19. Ahlberg G, Enochsson L, Gallagher AG, Hedman L, Hogman C, McClusky DA 3rd et al. Proficiency-based virtual reality training significantly reduces the error rate for residents during their first 10 laparoscopic cholecystectomies. Am J Surg. 2007 Jun;193(6):797-804.

20. Ritter EM, Kindelan TW, Michael C, Pimentel EA, Bowyer MW. Concurrent validity of augmented reality metrics applied to the fundamentals of laparoscopic surgery. Surg Endosc. 2007;21:1441-5.

21. Herron DM, Lantis JC, Maykel, Basu C, Schwaitzberg SD.The 3-D monitor and head mounted display. A quantitative evaluation of advanced laparoscopic viewing techniques. Surg Endosc. 1999;13:751-5. 